\title{
Cmambu
}

\section{ЧУВСТВИТЕЛЬНОСТЬ К СПРАВЕДЛИВОСТИ И ЕЕ ПОСЛЕДСТВИЯ ДЛЯ ЛИЧНОСТИ}

\author{
А.А. АДАМЯН \\ ${ }^{a}$ Национальный исследовательский университет «Высшая школа экономики», 101000, Россия, \\ Москва, ул. Мяснищкая, д. 20
}

\section{Резюме}

Справедливость представляет собой социальную ценность, которая играет важную роль в распределении разнообразных ресурсов, поддержании устойчивости общества, поэтому общество заинтересовано в ее укреплении и восприимчивости отдельных членов общества к фактам нарушения справедливости. Однако феномены, которые благоприятны для общества в целом, не всегда способствуют благополучию отдельного индивида. Чувствительность к справедливости представляет собой черту личности (диспозицию), которая отражает индивидуальные различия в готовности воспринимать случаи несправедливости и в интенсивности когнитивных, эмоциональных и поведенческих реакций на несправедливость. В настоящей статье исследуется, как чувствительность к справедливости связана с показателями эмоционального состояния, самоуважения и устойчивости личности. Показано, что чувствительность к справедливости положительно связана с депрессивной симптоматикой, в то время как ее вклад в оценку субъективного благополучия достаточно слаб. Обнаружено, что эта связь опосредована переменными самоуважения и устойчивости личности. Продемонстрировано также, что характеристики этой связи варьируют в зависимости от позиции субъекта в гипотетической ситуации нарушения справедливости (жертвы, свидетеля, бенефициара или нарушителя). Наиболее сильный вклад в текущее психологическое состояние вносит чувствительность к справедливости с позиции жертвы. Этот вклад отчасти опосредован негативной связью чувствительности к справедливости с самоуважением и устойчивостью. В исследовании обсуждается также гендерная специфика связи чувствительности к справедливости с показателями эмоционального состояния, самоуважения, устойчивости; в целом подтверждается, что для женской выборки по сравнению с мужской чувствительность к справедливости в большей степени является предиктором негативного эмоционального состояния, сниженного самоуважения и субъективного благополучия.

Ключевые слова: чувствительность к справедливости, позиция жертвы, позиция свидетеля, позиция бенефициара, позиция нарушителя, самоуважение, устойчивость личности, депрессивные симптомы, гендерные различия. 


\section{Введение}

Для фиксации устойчивых индивидуальных особенностей реагирования на ситуации нарушения справедливости М. Шмиттом в 1990-е гг. была разработана концепция чувствительности к свершившейся несправедливости (Нартова-Бочавер, Астанина, 2014a; Schmitt, Dörfel, 1999). Со временем термин с целью упрощения формулировки трансформировался в «чувствительность к справедливости» (ЧС). В настоящий момент она рассматривается как черта личности (диспозиция), которая отражает индивидуальные различия в восприимчивости к случаям несправедливости и в интенсивности когнитивных, эмоциональных и поведенческих реакций на несправедливость. ЧС включает в себя четыре компонента: а) частоту, с которой человек отмечает несправедливость в окружающей действительности, б) интенсивность эмоциональных реакций на несправедливость, в) склонность к руминациям на тему несправедливости, г) мотивацию к восстановлению справедливости. В концепции учитываются различные позиции, которые может занимать личность по отношению к несправедливости: жертвы, свидетеля, бенефициара и нарушителя - и в соответствии с ними выделяются различные типы ЧС $\left(\mathrm{Ч}_{\text {жертвв }}, \mathrm{Ч}_{\text {свид, }}, \mathrm{Ч}_{\text {бенефф }}, \mathrm{Ч}_{\text {наруш }}\right)$.

Вопрос о роли ЧС в отношении характеристик эмоционального состояния и качества жизни до сих пор затрагивался лишь в отдельных исследованиях, и не всегда в центре внимания ученых оказывались все аспекты ЧС. В первую очередь исследователи обращались к проблеме эмоционального неблагополучия в контексте позиции жертвы. Сфокусированность на проблеме учета своих интересов, восприимчивость к признакам ущемления собственных прав окружающими приводят к более частому переживанию негативных эмоций печали, беспомощности. В исследовании М. Шмитта и М. Дорфеля (Schmitt, Dörfel, 1999), проведенном среди сотрудников фабрики в Германии, было

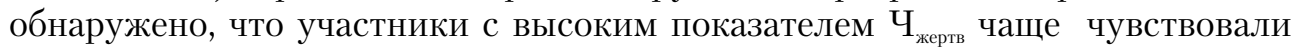
себя плохо на работе и брали больничный в ситуации, когда считали, что с ними несправедливо обходятся, также было отмечено большее количество случаев несправедливого обращения в отношении этих участников (конечно, отчасти объяснение этого феномена может быть связано с их большим вниманием к таким случаям и их более точной регистрацией). В исследовании с участием учителей (см: Baumert, Schmitt, 2016) $Ч_{\text {жертв }}$ была связана с высокими показателями депрессии, оцениваемой по самоотчетам. В исследовании А. Баумерт, К. Байрлайн с соавт. также была обнаружена отрицательная связь $Ч_{\text {жертв }}$ с удовлетворенностью жизнью и с доверием к людям, самоэффективностью, внутренним локусом контроля (Baumert et al., 2014), на основании чего можно предполагать, что содержание $\bigcup_{\text {жертв }}$ включает в себя переживание собственной уязвимости, страх подвергнуться несправедливому обращению, которые наносят ущерб психологическому благополучию. Однако не только $Ч_{\text {жертв }}$ оказалась связана со сниженными показателями психологического благополучия. Высокие показатели $\mathrm{Ч}_{\text {свил }}$ среди учителей (см: Baumert, Schmitt, 2016) были связаны с депрессивными тенденциями. В исследовании 
A. Баумерт с соавт. (Baumert et al., 2014) отрицательные корреляции с удовлетворенностью жизнью наблюдались и для $\mathrm{Ч}_{\text {бенеф }}$ и $\mathrm{Ч}_{\text {свия }}$ хотя и были менее выраженными, чем для Ч жерв. В русле интереса к культурным особенностям конструктов, связанных со справедливостью (Nartova-Bochaver et al., 2018; Wu et al., 2014), было проведено исследование связи $Ч_{\text {жертв }}$ с показателями психологического благополучия также на российской выборке (НартоваБочавер, Астанина, 2014б). В нем ЧС рассматривалась в широкой системе коррелятов, которая не ограничивалась характеристиками аффекта и субъективными оценками благополучия, но включала такие связанные с психологическим благополучием личности понятия, как аутентичность, суверенность психологического пространства, самоуважение, личностная устойчивость. Были получены интересные результаты относительно гендерных различий в

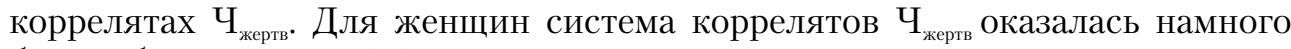
более обширной и дифференцированной, чем для мужчин.

Таким образом, рассмотрение ЧС в контексте ее связи с эмоциональным состоянием открывает пути к пониманию содержательной наполненности мира, в котором живет человек с высокой восприимчивостью к несправедливости. В то же время принципиальным является вопрос о том, как позиция индивида в ситуации взаимодействия, воспринимаемой им как несправедливая (роль жертвы, бенефициара, свидетеля или нарушителя), влияет на степень его эмоциональной реакции, а также о том, можно ли выделить медиаторы, опосредующие эту связь, и различаются ли они в зависимости от позиции.

\section{Эмпирическое исследование}

Целью нашего исследования является изучение взаимосвязей ЧС с позиций жертвы, свидетеля, бенефициара и нарушителя с эмоциональным состоянием и субъективной оценкой психологического благополучия, а также возможных опосредующих эти связи факторов с учетом гендерных различий. В исследовании участвовал 1001 респондент (772 женского пола, 229 мужского), студенты московских вузов. В батарею методик, которую заполняли все участники, вошли: опросник Чувствительности к справедливости (Justice sensitivity inventory), включающий подшкалы Чувствительности к справедливости с позиции жертвы, свидетеля, бенефициара и нарушителя (Victim Justice sensitivity subscale, Observer Justice sensitivity subscale, Beneficiary Justice Sensitivity subscale, Perpetrator Justice sensitivity subscale) (Адамян и др., 2018), шкала Депрессии (Center for Epidemiologic Studies Depression Scale, CES-D) (Андрющенко и др., 2003), шкала Устойчивости Коннор-Дэвидсона (Connor-Davidson Resilience Scale, CD-RISC) (Campbell-Sills, Stein, 2007), шкала Самоуважения (SelfEsteem scale) (Прихожан, 2002; Rosenberg, 1979). Часть респондентов также заполняли краткую форму отчета о позитивных и негативных чувствах (ShortForm of the Positive and Negative Affect Schedule, PANAS) (Thompson, 2007) (731 человек, из них 561 женского пола) и шкалу Психологического благополучия Варвик-Эдинбург (Warwick-Edinburgh Mental Well-being Scale, WEMWBS) (Tennant et al., 2007) (785 человек, из них 608 женского пола). 
Шкала депрессии CES-D была разработана для диагностики депрессивных симптомов в общей популяции (Radloff, 1977). Она включает, помимо вопросов, касающихся эмоционального состояния - негативного и позитивного аффекта, соматизации и снижения активности, также вопросы по поводу сложностей межличностного взаимодействия, что может быть специфически характерно для людей с высокой восприимчивостью к ситуациям несправедливости. Показатель психологического благополучия по шкале ВарвикЭдинбург включает также аспекты не только положительных эмоций, самооценку психологического функционирования (автономии, самопринятия, компетентности, личностного роста), но и продуктивных межличностных отношений (Шевеленкова, Фесенко, 2005; Tennant et al., 2007). Также в исследование были включены стабильные характеристики - самоуважение и устойчивость личности (понимаемая как способность эффективно противостоять стрессовым ситуациям и адаптироваться). Самоуважение как общая самооценка, которая связана с чувством собственного достоинства, ощущением собственной ценности, воздействующая на характер всех контактов личности с окружающими (Почебут, Мейжис, 2016, с. 117), и устойчивость как оцениваемая в самоотчете способность справляться со стрессовыми ситуациями, противостоять им, рассматривались не только непосредственно в их связи с измерениями ЧС, но и как возможные медиаторы связи ЧС и характеристик эмоционального состояния и субъективных оценок благополучия. Можно предположить, что человек с высокими показателями ЧС, чаще сталкиваясь с ситуациями, воспринимаемыми как несправедливые, и часто будучи не в состоянии на них повлиять, может таким образом подтачивать свою веру в способность справляться со сложностями - устойчивость и положительную оценку собственной личности - самоуважение, что в свою очередь негативно влияет на благополучие. И эти связи полностью или частично объясняют негативное влияние ЧС на показатели благополучия.

В продолжение линии исследований, намеченной С.К. Нартовой-Бочавер и Н.Б. Астаниной (Нартова-Бочавер, Астанина, 2014б), в данной работе изучалась также гендерная специфика связей аспектов ЧС с показателями эмоционального состояния и субъективными оценками благополучия.

\section{Гипотезы исследования}

1. ЧС с позиций жертвы, свидетеля, бенефициара и нарушителя отрицательно связана с показателями положительного эмоционального состояния и субъективными оценками благополучия. Для позиции жертвы связь является наиболее выраженной.

2. ЧС с позиций жертвы, свидетеля, бенефициара и нарушителя положительно связана с негативным аффектом и депрессивными симптомами. Наиболее высокие показатели связи наблюдаются для позиции жертвы.

3. ЧС с позиций жертвы, свидетеля, бенефициара и нарушителя отрицательно связана с показателями самоуважения и устойчивости личности 
4. У девушек и юношей различается выраженность связей между ЧС и показателями депрессии, позитивного и негативного аффекта, благополучия, а также самоуважения и устойчивости (для женской выборки связи более выражены).

5. Устойчивость личности и самоуважение выступают медиаторами связей между ЧС и показателями благополучия (связь измерений ЧС с показателями благополучия отчасти либо полностью объясняется их отрицательными связями с самоуважением, устойчивостью и положительными связями самоуважения и устойчивости с показателями благополучия), при этом степень медиации различается в зависимости от того, какая позиция ЧС рассматривается.

В исследовании использовались методы статистической обработки данных: описательные статистики, корреляционный анализ, регрессионный анализ.

\section{Результаты и обсуждение}

Сравнение показателей ЧС у юношей и девушек по критерию МаннаУитни обнаружило статистически значимые $(p<0.01)$ различия в уровнях ЧС по всем измерениям, кроме $Ч_{\text {жертв }}$ (таблица 1). Результаты согласуются с данными, полученными в предыдущих исследованиях (Schmitt et al., 2010; Schmitt et al., 2005).

В результате корреляционного анализа были выявлены положительные связи между всеми измерениями ЧС и депрессивными симптомами (таблица 2). Как и в исследовании М. Шмитта и М. Дорфеля (Schmitt, Dörfel, 1999), наи-

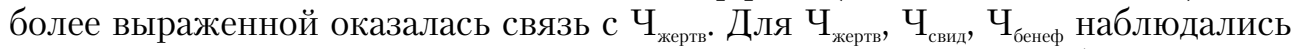
также значимые отрицательные корреляции с психологическим благополучием, однако как абсолютная величина связи, так и уровень значимости были ниже, чем для депрессии. Из показателей текущего аффекта только негативные эмоции оказались связаны с измерениями ЧС. Совершающаяся несправедливость заставляет человека реагировать негативными эмоциями, в то время как переживание позитивных эмоций остается незатронутым. В наименьшей степени с депрессией и негативным аффектом связана Ч Вероятно, в отличие от других позиций роль нарушителя является активной у человека, для которого важно самому поступать справедливо, в большинстве случаев есть возможность избежать ситуаций, в которых его будут терзать

Таблица 1

Средние значения показателей ЧС юношей и девушек

\begin{tabular}{|c|c|c|}
\hline Шкала/пол & Юноши & Девушки \\
\hline ЧС $_{\text {жертв }}$ & 28.2 & 29.52 \\
\hline ЧС $_{\text {свид }}$ & 26.3 & 28.34 \\
\hline ЧС бенеф & 22.7 & 24.72 \\
\hline ЧС $_{\text {наруш }}$ & 27.0 & 30.38 \\
\hline
\end{tabular}


Таблица 2

Корреляционные связи ЧС

\begin{tabular}{|c|c|c|c|c|}
\hline & $\mathbf{Y}_{\text {жертв }}$ & $\mathbf{Y}_{\text {свид }}$ & $\mathbf{Y}_{\text {бенеф }}$ & $\mathbf{Y}_{\text {наруш }}$ \\
\hline Устойчивость & $\begin{array}{l}-0.130^{* *} \\
-0.112 \\
-0.129 * *\end{array}$ & $\begin{array}{l}-0.065^{*} \\
-0.054 \\
-0.056\end{array}$ & $\begin{array}{l}-0.126^{* *} \\
-0.105 \\
-0.123^{* *}\end{array}$ & $\begin{array}{l}-0.102^{* *} \\
-0.105 \\
-0.083^{*}\end{array}$ \\
\hline Самоуважение & $\begin{array}{l}-0.214 * * \\
-0.179 * * \\
-0.222 * *\end{array}$ & $\begin{array}{l}-0.245^{* *} \\
-0.203^{* *} \\
-0.254^{* *}\end{array}$ & $\begin{array}{l}-0.278^{* *} \\
-0.266^{* *} \\
-0.278^{* *}\end{array}$ & $\begin{array}{l}-0.191^{* *} \\
-0.185^{* *} \\
-0.186^{* *}\end{array}$ \\
\hline Депрессия & $\begin{array}{l}0.280^{* *} \\
0.277^{*} * \\
0.276 * *\end{array}$ & $\begin{array}{l}0.243^{* *} \\
0.172^{* *} \\
0.258^{* *}\end{array}$ & $\begin{array}{l}0.211 * * \\
0.208 * * \\
0.205 * *\end{array}$ & $\begin{array}{l}0.181^{* *} \\
0.161^{*} \\
0.175^{* *}\end{array}$ \\
\hline $\begin{array}{l}\text { Позитивный } \\
\text { аффект }\end{array}$ & $\begin{array}{l}0.059 \\
0.166^{*} \\
0.019\end{array}$ & $\begin{array}{l}0.052 \\
0.054 \\
0.046\end{array}$ & $\begin{array}{r}-0.009 \\
0.042 \\
-0.031\end{array}$ & $\begin{array}{l}-0.006 \\
-0.003 \\
-0.017\end{array}$ \\
\hline $\begin{array}{l}\text { Негативный } \\
\text { аффект }\end{array}$ & $\begin{array}{l}0.257 * * \\
0.269 * * \\
0.250 * *\end{array}$ & $\begin{array}{l}0.160^{* *} \\
0.121 \\
0.165^{* *}\end{array}$ & $\begin{array}{l}0.106^{* *} \\
0.138 \\
0.090^{*}\end{array}$ & $\begin{array}{l}0.090^{*} \\
0.158^{*} \\
0.056\end{array}$ \\
\hline Благополучие & $\begin{array}{l}-0.153^{* *} \\
-0.12 \\
-0.165^{* *}\end{array}$ & $\begin{array}{c}-0.095^{* *} \\
0.033 \\
-0.146^{* *}\end{array}$ & $\begin{array}{c}-0.087^{*} \\
0.011 \\
-0.129 * *\end{array}$ & $\begin{array}{c}-0.046 \\
0.064 \\
-0.089 *\end{array}$ \\
\hline
\end{tabular}

Примечание. Значения указаны последовательно: для выборки в целом, для юношей и девушек.

${ }^{*} p<0.05,{ }^{* *} p<0.01$.

угрызения совести. Позиция жертвы, наоборот, предполагает наименьшую возможность противостоять обстоятельствам. Характеристики связей показателя депрессии с различными ЧС у юношей и девушек существенно не отличаются. Негативный аффект коррелирует с Ч наруш только у юношей, у девушек связь не является значимой даже на уровне статистической тенденции и ниже по абсолютному значению. При этом психологическое благополучие отрицательно связано с ЧС у девушек. По-видимому, для женщин существование несправедливости вообще (не только в отношении их самих) подрывает основы положительного отношения к себе и к собственной жизни. Таким образом, первая гипотеза исследования подтвердилась частично, вторая подтвердилась полностью.

Были обнаружены отрицательные связи между всеми измерениями ЧС и самоуважением. Самые высокие показатели связи - у $Ч_{\text {свид }}$ и $Ч_{\text {бенеф. }}$ Вероятно, наблюдение несправедливости в отношении другого в случае неспособности что-либо изменить может ассоциироваться с переживанием слабости, а также идти вразрез с соблюдением моральных норм, которое часто лежит в основе самоуважения. Роль бенефициара, получающего что-то без усилий, может предполагать радость от стечения обстоятельств, но позиция, которую занимает человек, чувствительный к несправедливости, как бенефициар, - это 
позиция того, кто не готов принимать великодушие судьбы, кто должен заслужить все сам, вероятно, в том числе с целью укрепления самоуважения. Переживание несправедливости с позиции жертвы может быть губительно для самоуважения из-за ощущения собственной слабости и уязвимости, если в системе представлений человека сила является условием самоуважения. Психологическая устойчивость, оцениваемая с помощью опросника КоннорДэвидсона, также оказалась отрицательно связана со всеми измерениями ЧС, кроме $Ч_{\text {свид }}$ хотя все абсолютные значения связи ниже, чем для самоуважения. С одной стороны, восприимчивость к ситуациям несправедливости, приносящая негативные эмоциональные переживания, может делать человека субъективно более уязвимым, нарушать его представления о себе как о том, кто является «сильным человеком», «может справиться с чем угодно». С другой стороны, представление о себе как о более слабом делает необходимым отслеживание ситуаций потенциальной угрозы, в частности ситуаций несправедливости. Третья гипотеза исследования в целом подтвердилась.

Для девушек абсолютные показатели связи самоуважения с аспектами ЧС несколько выше, чем для юношей. В статье, посвященной исследованию коррелятов $Ч_{\text {жертв}}$, С.К. Нартова-Бочавер и Н.Б. Астанина (Нартова-Бочавер, Астанина, 2014б) указывают, что более широкая сеть связей Ч неблагоприятными с точки зрения адаптации характеристиками может быть связана с меньшей подготовленностью девушек к условиям конкуренции, возможности неудачи, но в то же время различие может объясняться разными системами морали, в которых живут мужчины и женщины. Для мужчин, которые руководствуются категорией справедливости, ситуация несправедливости - это ситуация нарушения правил, неизбежно встречающаяся в жизни. Для женщин же, руководствующихся моралью заботы, несправедливость характеристика взаимоотношений между людьми, в которых потеряна идея заботы о другом, признания его ценности. Наиболее выраженные отличия в степени связи ЧС с самоуважением у девушек и юношей характерны для позиции жертвы. Отсутствие значимой связи ЧС с устойчивостью у юношей при наличии ее у девушек с учетом различий в объемах выборок следует с осторожностью интерпретировать как содержательное различие.

Четвертая гипотеза частично подтвердилась, при этом было обнаружено, что для юношей Ч ни, чем для девушек.

На следующем этапе анализа данных был проведен регрессионный анализ с исследованием возможного опосредования связей между отдельными показателями ЧС и переменными депрессии, негативного аффекта и благополучия (позитивный аффект не рассматривался из-за отсутствия значимых корреляций с ЧС). В качестве медиаторов выступали самоуважение и устойчивость.

Для показателя депрессивных симптомов в присутствии медиаторов самоуважения и устойчивости - значимыми являются как прямой, так и непрямой эффекты Ч ции жертвы источником негативных эмоций, обусловленных ЧС, является в 
большей степени переживание по поводу нанесенного ущерба или по поводу нарушенных отношений с другим человеком, в меньшей степени - пострадавшее из-за попадания в ситуацию несправедливости самоуважение и оценка собственной способности справляться со сложными ситуациями. Прямой

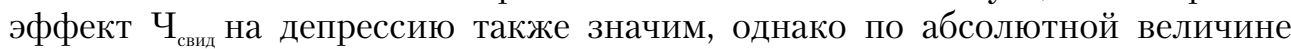
больше та часть, которая опосредована самоуважением и устойчивостью (рисунок 1б). Для $Ч_{\text {бенеф }}$ прямое влияние на депрессию не является статистически значимым и является еще более низким по сравнению с опосредованным (рисунок 1в). Прямое влияние $Ч_{\text {наруш }}$ на депрессию является значимым на уровне статистической тенденции, однако прямой эффект существенно ниже опосредованного (рисунок 1г). Таким образом, для аспектов ЧС, связанных с просоциальными чертами личности (Baumert et al., 2014), негативное влияние на эмоциональное состояние является в большей степени опосредованным ударом по представлениям о себе - самоуважению и отчасти по устойчивости. Ситуации несправедливости, где человек не является жертвой, но выступает в роли свидетеля, бенефициара или же нарушителя, видимо, создают конфликт между идеальными представлениями о себе и своими реальными

Рисунок 1

\section{Результаты применения регрессионного анализа (зависимая переменная - депрессия,}

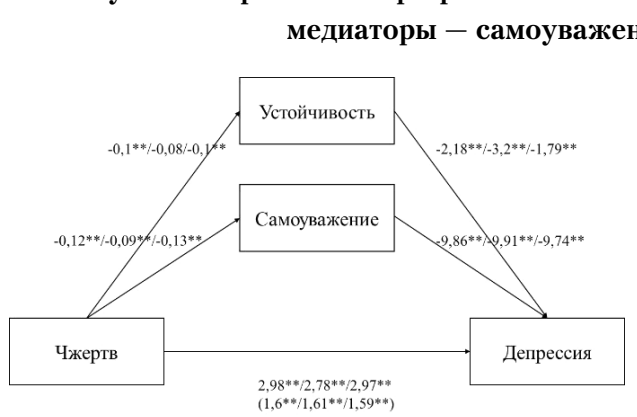

$\mathrm{a}$

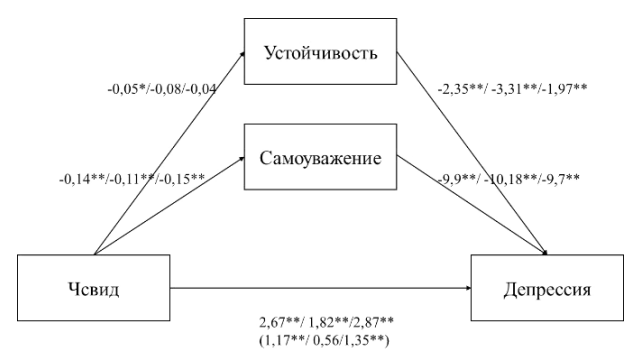

б

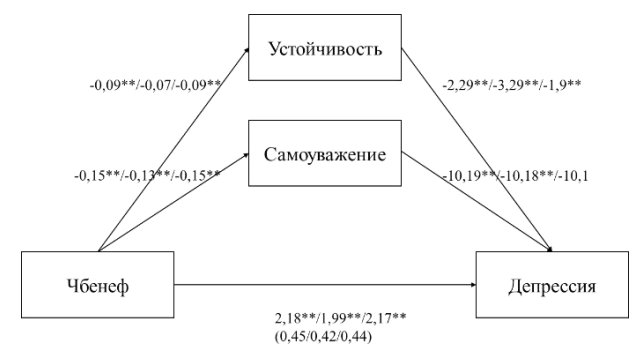

B

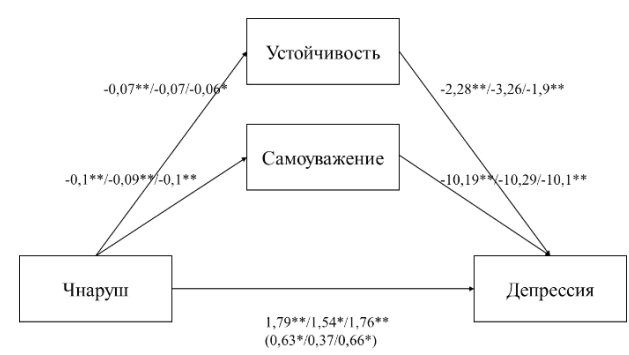

$\Gamma$

Примечание. В скобках указан прямой эффект ЧС (при контроле переменных самоуважения и устойчивости), вне скобок - общий эффект регрессии. Значения указаны последовательно: для выборки в целом, для юношей и для девушек. $\mathrm{N}=1001 / 229 / 772$.

${ }^{*} p<0.05,{ }^{* *} p<0.01$. 
возможностями или действиями, вызывая негативные переживания. Гендерная специфика проявляется наиболее ярко для роли свидетеля несправедливости. На уровень депрессии у девушек подобные ситуации оказывают большее влияние, при этом различие связано в первую очередь с эффектом, который не опосредован показателем самоуважения (связь между $Ч_{\text {свид и }}$ устойчивостью теряет статистическую значимость при уменьшении объема выборки). Можно предположить, что влияние может быть связано с эмпатией - переживанием боли другого человека как своей собственной. Связь Ч бенеф с депрессией полностью опосредована промежуточными переменными (в первую очередь самоуважением) как для девушек, так и для юношей. Переживание потери собственного достоинства в ситуации получения незаслуженного вознаграждения вызывает депрессивные проявления. Уровень $Ч_{\text {наруш }}$ как для девушек, так и для юношей влияет на уровень депрессии в основном опосредованно - через изменение отношения к себе. Но на женской выборке неопосредованный эффект $Ч_{\text {наруш }}$ выше, чем на мужской, и остается значимым на уровне тенденции при контроле медиаторов. Можно предполагать, что эта составляющая также связана с эмпатией в отношении жертвы несправедливости.

Связь ЧС с переживанием негативного аффекта менее выражена, чем связь

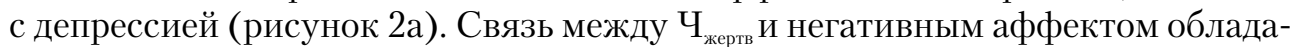
ет наибольшим среди измерений ЧС общим эффектом, при этом она в наименьшей степени опосредована переменными самоуважения и устойчивости, что вновь свидетельствует об особой специфике переживания несправедливости в отношении себя, требующей дополнительного исследования ее механизмов. Для других измерений ЧС в случае наличия значимого общего эффекта он достигался за счет опосредования показателем самоуважения (рисунки 2б, 2в, 2г). Устойчивость в меньшей степени связана с переживанием аффекта, поэтому не оказалась значимым медиатором. Гендерная специфика ярко проявилась для позиции нарушителя: для женской выборки не существует значимой связи между $Ч_{\text {наруш }}$ и переживанием негативного аффекта, в то время как для мужской связь присутствует и опосредована самоуважением. Можно предположить, что для мужчин существует аффективно заряженная модель справедливого поведения, нарушение которой вызывает негативные эмоции.

Исследование связи между ЧС и благополучием показало, что для Чжертв $Ч_{\text {свид }}$ общий эффект ЧС связан исключительно с опосредованием самоуважением и устойчивостью (рисунки За, 3б). На первый взгляд парадоксальный

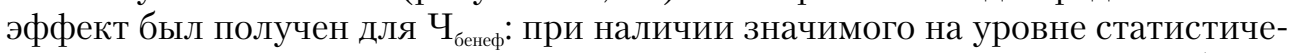
ской тенденции прямого эффекта ЧС его знак противоположен знаку общего эффекта (рисунок Зв). Возможно, хотя суммарное влияние $Ч_{\text {бенеф }}$ на благополучие негативно, отрицательный эффект достигается за счет изменения самоотношения, однако при этом есть положительная составляющая связи, которую можно объяснить эмоциями по поводу хоть и незаслуженного, но выигрыша в ситуации. ЧС с позиции нарушителя не влияет на благополучие. На мужской выборке отсутствуют значимые связи между ЧС и благополучием, на женской выборке связи существуют и полностью опосредуются самоуважением и 
Рисунок 2

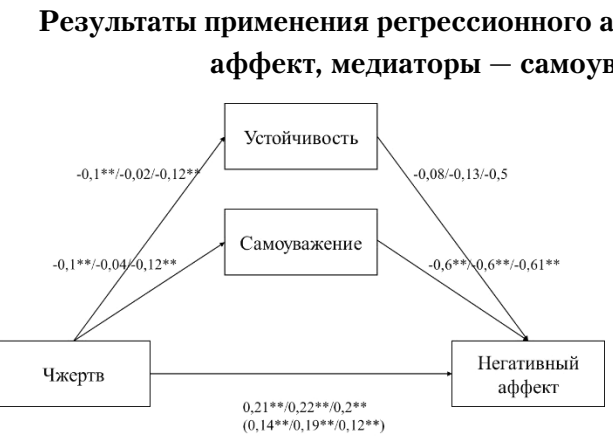

a

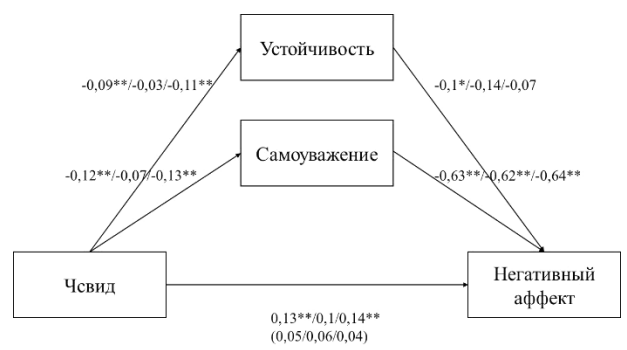

б

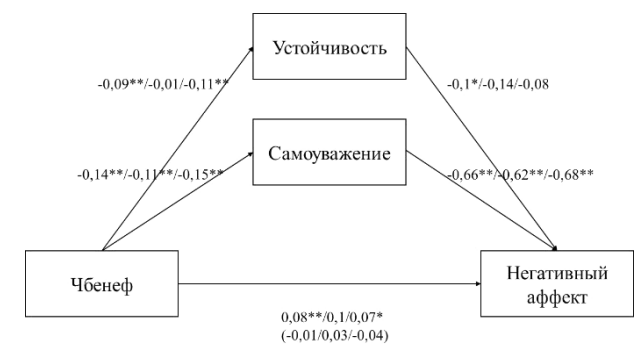

B

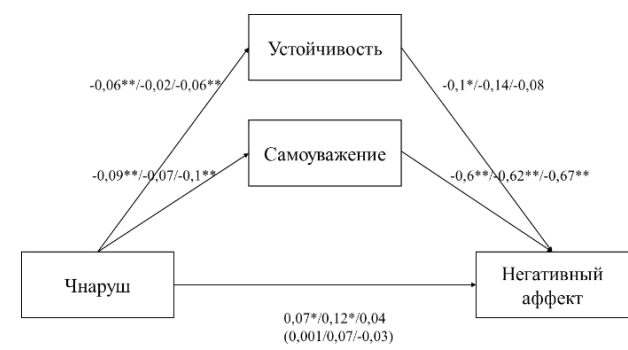

$\Gamma$

Примечание. В скобках указан прямой эффект ЧС (при контроле переменных самоуважения и устойчивости), вне скобок - общий эффект регрессии. Значения указаны последовательно: для выборки в целом, для юношей и для девушек. $\mathrm{N}=731 / 165 / 566$.

${ }^{*} p<0.05,{ }^{* *} p<0.01$.

устойчивостью (рисунки За, Зб, Зв, Зг), т.е. если у юношей влияние ЧС ограничивается сферой негативных переживаний, то у девушек ЧС связана с гендерно специфическими особенностями представлений о себе и через них опосредованно влияет на благополучие.

Таким образом, пятая гипотеза исследования частично подтвердилась.

\section{Заключение}

В результате исследования связи восприимчивости к несправедливости с различных позиций в ситуации межличностного взаимодействия были получены ответы на некоторые вопросы относительно механизмов влияния ЧС на психологическое состояние и одновременно обозначены перспективы дальнейших исследований. В целом ЧС с каждой из занимаемых в ситуации несправедливости позиций связана с негативной стороной человеческого существования: отрицательным аффектом и депрессивной симптоматикой, не влияя на положительный аффект и оказывая воздействие на оценку психологического благополучия лишь у девушек. Также ЧС оказалась негативно связана 
Рисунок 3

Результаты применения регрессионного анализа (зависимая переменная - благополучие, медиаторы - самоуважение, устойчивость личности)

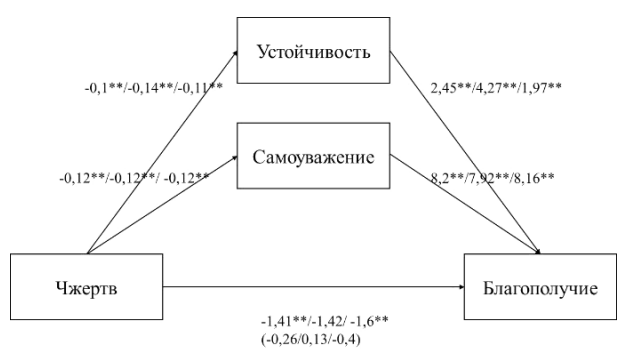

a

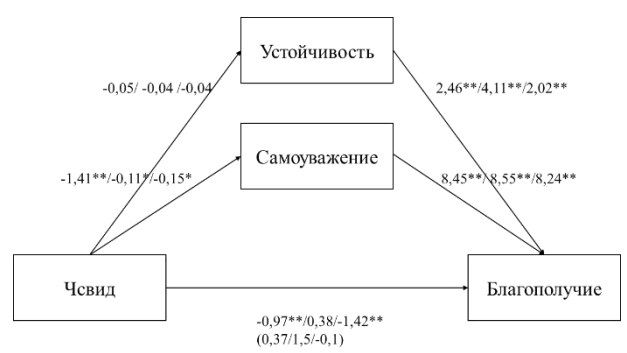

6

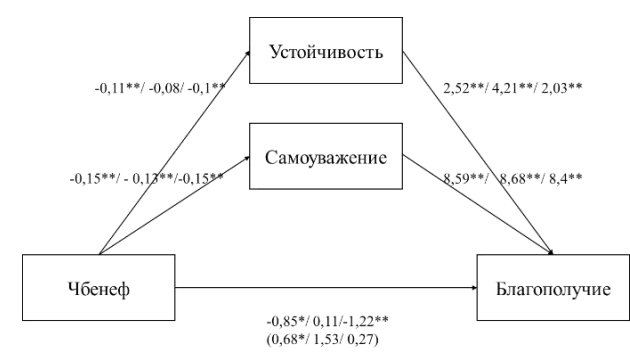

B

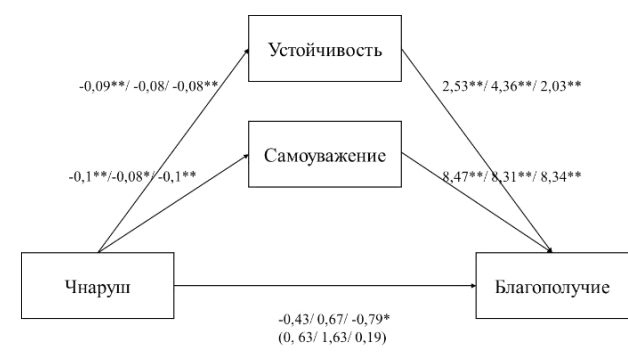

$\Gamma$

Примечание. В скобках указан прямой эффект ЧС (при контроле переменных самоуважения и устойчивости), вне скобок - общий эффект регрессии. Значения указаны последовательно: для выборки в целом, для юношей и для девушек. $\mathrm{N}=785 / 177 / 608$.

${ }^{*} p<0.05,{ }^{* *} p<0.01$.

с показателем самоуважения и с устойчивостью личности. Наиболее важным предиспозиционным фактором для негативного аффекта и депрессии является восприимчивость к несправедливости с позиции жертвы. Влияние Ч депрессивные симптомы и негативный аффект лишь отчасти объясняется медиаторами - самоуважением и устойчивостью. Дальнейшие исследования помогут выяснить, опосредовано ли это влияние переживанием потери, негативным изменением отношения к людям или чем-то другим. Влияние восприимчивости к несправедливости с позиции бенефициара на депрессивную симптоматику полностью объясняется изменением представления о себе. У девушек $Ч_{\text {свид }}$ в большей степени, чем у юношей, влияет на симптомы депрессии и негативного аффекта, при этом в значительной степени влияние не объясняется медиаторами. Связь ЧС с эмпатией (Baumert et al., 2014), традиционно более высокие показатели эмпатии у женщин позволяют предполагать, что склонность сопереживать другим может быть медиатором связи между $Ч_{\text {свид }}$ и депрессией. Влияние $Ч_{\text {свид}}, Ч_{\text {бенеф }}$ и $Ч_{\text {наруш }}$ на негативный аффект на выборке в целом полностью объясняется через связи с самоуважением: существование несправедливости, на которую человек не всегда может повлиять, 
подрывает представление о самом себе и негативно сказывается на эмоциональном состоянии. Влияние ЧС на благополучие отмечается только у девушек, оно полностью опосредуется самоуважением и устойчивостью.

Перспективы исследования видятся в области расширения спектра характеристик, которые помогут далее прояснить связи между восприимчивостью к справедливости с различных позиций и негативными эмоциональными последствиями для личности.

\section{Литература}

Адамян, А. А., Нартова-Бочавер, С. К., Шмитт, М. (2018). Опросник «Чувствительность к справедливости»: валидизация опросника на российской выборке. Психологический журнал, 39(4), 105-116.

Андрющенко, А. В., Дробижев, М. Ю., Добровольский, А. В. (2003). Сравнительная оценка шкал CES-D, BDI и HADS (d) в диагностике депрессий в общемедицинской практике. Журнал неврологии и психиатрии им. С. С. Корсакова, 103(5), 11-18.

Нартова-Бочавер, С. К., Астанина, Н. Б. (2014, а). Психологические проблемы справедливости в зарубежной персонологии: теории и эмпирические исследования. Психологический журнал, 35(1), 16-32.

Нартова-Бочавер, С. К., Астанина, Н. Б. $(2014$, б). «Униженность и оскорбленность» как черта личности: феноменологический анализ позиции жертвы.Социальная психология $u$ общество, 5(2), 13-26.

Почебут, Л. Г., Мейжис, И. А. (2016). Социальная психология. СПб.: Питер.

Прихожан, А. М. (2002). Диагностика личностного развития детей подросткового возрасma. М.: АНО «ПЭБ».

Шевеленкова, Т. Д., Фесенко, П. П. (2005). Психологическое благополучие личности (обзор основных концепций и методика исследования). Психологическая диагностика, 3, 95-129.

Ссылки на зарубежные источники см. в разделе References после англоязычноо блока.

Адамян Анна Андреевна - аспирант, департамент психологии, факультет социальных наук, Национальный исследовательский университет «Высшая школа экономики».

Сфера научных интересов: психология личности, чувствительность к справедливости, психологическое благополучие.

Контакты: anna.a.adamyan@yandex.ru 


\title{
Justice Sensitivity and Its Consequences for an Individual
}

\author{
A.A. Adamyan ${ }^{a}$ \\ ${ }^{a}$ National Research University Higher School of Economics, 20 Myasnitskaya Str., Moscow, 101000, \\ Russian Federation
}

\begin{abstract}
Justice is a social value that plays an important role in the distribution of various resources, maintaining the sustainability of society, therefore society is interested in strengthening it, and in the sensitivity of members of society to the facts of violations of justice. However, phenomena that are favorable for society do not always contribute to the well-being of the individual. Justice sensitivity is a personality trait (disposition) that reflects individual differences in the readiness to perceive injustice and in the intensity of cognitive, emotional, and behavioral responses to injustice. This article explores how justice sensitivity is related to indicators of emotional state, self-esteem and personal resilience. It is shown that justice sensitivity is positively associated with depressive symptoms, while its impact on subjective well-being is rather weak. It was found that this relationship is mediated by the variables of self-esteem and personal resilience. Also it was demonstrated that characteristics of this connection vary depending on the position of the subject in a hypothetical situation of a violation of justice (victim, observer, beneficiary, perpetrator). Justice sensitivity from the victim's perspective makes the most powerful contribution to the current psychological state. This contribution is partly mediated by a negative relationship between justice sensitivity and self-esteem and resilience. The study also discusses gender specificity of the relationship of justice sensitivity to indicators of emotional state, self-esteem, and sustainability; in general, it is confirmed that in women justice sensitivity is a more strong predictor of negative emotional states, reduced self-esteem and subjective well-being.
\end{abstract}

Keywords: justice sensitivity, victim perspective, observer perspective, beneficiary perspective, perpetrator perspective, gender psychology, self-esteem, resilience, depressive symptoms, gender differences.

\section{References}

Adamyan, A. A., Nartova-Bochaver, S. K., \& Shmitt, M. (2018). The "Justice Sensitivity Questionnaire”: validation in a Russian speaking sample. Psikhologicheskii Zhurnal, 39(4), 105-116. (in Russian)

Andryshchenko, A. V., Drobizhev, M. Yu., \& Dobrovolsky, A. V. (2003). A comparative validation of the scale CES-D, BDI, HADS(d) in diagnosis of depressive disorders in general medical practice. Zhurnal Nevrologii i Psikhiatri imeni S. S. Korsakova, 103(5), 11-18. (in Russian) 
Baumert, A., \& Schmitt, M. (2016). Justice sensitivity. In C. Sabbagh \& M. Schmitt (Eds.), Handbook of social justice theory and research (pp. 161-180). New York: Springer.

Baumert, A., Beierlein, C., Schmitt, M., et al. (2014). Measuring four perspectives of justice sensitivity with two items each. Journal of Personality Assessment, 96(3), 380-390. doi: 10.1080/00223891.2013.836526

Campbell-Sills, L., \& Stein, M. B. (2007). Psychometric analysis and refinement of the ConnorDavidson resilience scale (CD-RISC): validation of a 10-item measure of resilience. Journal of Traumatic Stress: Official Publication of The International Society for Traumatic Stress Studies, 20(6), 1019-1028. doi:10.1002/jts.20271

Nartova-Bochaver, S. K., \& Astanina, N. B. (2014, a). Theories and empirical research on justice in the foreign personality psychology. Psikhologicheskii Zhurnal, 35(1), 16-32. (in Russian)

Nartova-Bochaver, S. K., \& Astanina, N. B. (2014, b). "Unizhennost' i oskorblennost”" kak cherta lichnosti: fenomenologicheskii analiz pozitsii zhertvy ["Humiliation and insult" as a personality trait: a phenomenological analysis of the position of a victim]. Sotsial'naya Psikhologiya $i$ Obshchestvo, 5(2), 13-26. (in Russian)

Nartova-Bochaver, S., Donat, M., Astanina, N., \& Rüprich, C. (2018). Russian adaptations of General and Personal Belief in a Just World Scales: Validation and psychometric properties. Social Justice Research, 31(1), 61-84. doi:10.1007/s11211-017-0302-5

Pochebut, L. G., \& Meizhis, I. A. (2016). Sotsial'naya psikhologiya [Social Psychology]. Saint Petersburg: Piter. (in Russian)

Prikhozhan, A. M. (2002). Diagnostika lichnostnogo razvitiya detei podrostkovogo vozrasta [Diagnosis of personal development in adolescent children]. Moscow: ANO «PEB». (in Russian)

Radloff, L. S. (1977). The CES-D scale: A self-report depression scale for research in the general population. Applied Psychological Measurement, 1(3), 385-401. doi: 10.1177/014662167700100306

Rosenberg, M. (1979). Conceiving the Self. New York: Krieger Publishing Company.

Schmitt, M., Baumert, A., Gollwitzer, M., et al. (2010). The justice sensitivity inventory: Factorial validity, location in the personality facet space, demographic pattern, and normative data. Social Justice Research, 23(2), 211-238. doi: 10.1007/s11211-010-0115-2

Schmitt, M., \& Dörfel, M. (1999). Procedural injustice at work, justice sensitivity, job satisfaction and psychosomatic well-being. European Journal of Social Psychology, 29(4), 443-453.

Schmitt, M., Gollwitzer, M., Maes, J., \& Arbach, D. (2005). Justice sensitivity. European Journal of Psychological Assessment, 21(3), 202-211.

Shevelenkova, T. D., \& Fesenko, P. P. (2005). Psikhologicheskoe blagopoluchie lichnosti (obzor osnovnykh kontseptsii i metodika issledovaniya) [Psychological well-being of the individual (a review of basic concepts and research methods)]. Psikhologicheskaya Diagnostika, 3, 95-129. (in Russian)

Tennant, R., Hiller, L., \& Fishwick, R., et al. (2007). The Warwick-Edinburgh Mental Well-Being Scale (WEMWBS): development and UK validation. Health and Quality of Life Outcomes, 5(1), 63 . 
Thompson, E. R. (2007). Development and validation of an internationally reliable short-form of the Positive and Negative Affect Schedule (PANAS). Journal of Cross-Cultural Psychology, 38(2), 227-242.

Wu, M. S., Schmitt, M., \& Zhou, C., et al. (2014). Examining self-advantage in the suffering of others: Cross-cultural differences in beneficiary and observer justice sensitivity among Chinese, Germans, and Russians. Social Justice Research, 27(2), 231-242.

Anna A. Adamyan - Ph.D. student, Department of Psychology, Faculty of Social Sciences, National Research University Higher School of Economics.

Research area: psychology of personality, justice sensitivity, psychological well-being.

E-mail: anna.a.adamyan@yandex.ru 